\title{
Racial differences in associations between baseline patterns of radiographic osteoarthritis and multiple definitions of progression of hip osteoarthritis: the Johnston County Osteoarthritis Project
}

Bridget Foley ${ }^{1,2}$, Rebecca J. Cleveland ${ }^{2,3}$, Jordan B. Renner 2,4 , Joanne M. Jordan $2,3,5,6$ and Amanda E. Nelson ${ }^{2,3^{*}}$

\begin{abstract}
Background: To identify baseline radiographic features that predict hip osteoarthritis ( $\mathrm{HOA})$ progression, and to explore differences in these associations by race.

Methods: Radiographs from the community-based Johnston County OA Project were scored using KellgrenLawrence (KL) grade and for presence and location of joint space narrowing (JSN), osteophytes, and subchondral changes. Associations between these features and HOA progression (increase of at least $1 \mathrm{KL}$ grade, interval hip replacement, range of motion [ROM, a reduction of $\geq 10^{\circ}$ in internal rotation], or disability [increase of $\geq 0.2$ in Health Assessment Questionnaire scores], or Any of these) were assessed using logistic regression, adjusting for age, gender, race, hip injury, BMl, education, smoking and follow-up time, accounting for multiple comparisons. Race interactions were assessed and analyses stratified as indicated.

Results: The sample $(n=1,422)$ included $40 \%$ men and $26 \%$ African American (AA) participants, with mean age 61 years and BMI $29 \mathrm{~kg} / \mathrm{m}^{2}$. The baseline frequency of radiographic hip OA (RHOA) between Caucasians and AAs was similar (23\%), although some radiographic features differed. AAs were more likely to have progression defined by ROM or disability or Any progression; Caucasians were more likely to have RHOA progression. JSN, subchondral sclerosis, and medial osteophytes were associated with increased RHOA progression overall; JSN was associated with disability progression only in AAs, while lateral osteophytes were associated with ROM progression only in Caucasians.
\end{abstract}

Conclusions: AAs and Caucasians exhibited differences in the radiographic presentation and progression patterns of $\mathrm{HOA}$, with AAs reporting progressive pain and disability, while Caucasians had more RHOA progression.

Keywords: Hip, Osteoarthritis, Radiography, Disability

\footnotetext{
* Correspondence: aenelson@med.unc.edu

${ }^{2}$ Thurston Arthritis Research Center, University of North Carolina at Chapel Hill, 3300 Doc J. Thurston Bldg, CB \#7280, Chapel Hill, NC 27599-7280, USA ${ }^{3}$ Department of Medicine, University of North Carolina at Chapel Hill School of Medicine, 3300 Doc J. Thurston Bldg, CB \#7280, Chapel Hill, NC 27599-7280, USA

Full list of author information is available at the end of the article
} 


\section{Background}

Osteoarthritis (OA) is a common, chronic condition that affects $11 \%$ of the general adult population, and is the most common form of arthritis [1]. This percentage is expected to rise to $25 \%$ by 2030 , with $9.3 \%$ of the population reporting activity limitation due to some type of arthritis [2]. OA is a disease process that encompasses the entire joint, most commonly involving the hips, knees, and hands, causing considerable pain and disability $[3,4]$. Hip OA (HOA) in particular is associated with limitations in walking and climbing stairs and is the most common indication for total hip replacement surgery (THR) [5, 6]. Total hospital discharges for THR in the United States have been increasing in the last 20 years, with 286,324 discharges for THR in 1996, 369,372 in 2006 and 464,452 in 2011 (http://hcupnet.ahrq.gov).

There is a lack of standardization of the definitions of HOA, particularly for progression of this condition [7]. Progression in HOA has been measured in a variety of ways in previous studies, including (individually or in combination):

1. Decrease in radiographic joint space (either quantitative or qualitative) [8-19]

2. Increase in summary radiographic grade (KellgrenLawrence (KL) or others) [11-15, 20, 21]

3. Increase in total osteophyte score [11-15]

4. Receipt of THR [14-16, 18, 22, 23]

5. Worsening of self-reported pain or functioning [24]

Several baseline radiographic factors are associated with progression of HOA by various definitions. Joint space width $\leq 2.5 \mathrm{~mm}$ at study entry $[8,10,18]$ is associated with progression of HOA defined by further joint space narrowing (JSN) $[8,10,18]$ or THR [18]. Migration of the femoral head $[8,10]$, specifically superolateral migration [13, 23], has been associated with progression of HOA defined by progressive JSN $[8,10,13]$, increase in summary grade [13], increase in total osteophyte score [13], or THR [8, 23]. Osteophytes have been associated with progression of $\operatorname{HOA}[13,23]$ as defined by progressive JSN [13], increase in summary grade [13], increase in total osteophyte score [13], or THR [23]. Baseline hip pain [10, 13, 18, 23, 25] and increased disability scores [18] have also been associated with progression of HOA defined by progressive JSN [13, 18], increase in summary grade [13], increase in total osteophyte score [13] or THR [18, 23].

Although no significant difference in HOA prevalence was seen in the Johnston County OA Project (JoCo OA) $[26,27]$ or the First National Health and Nutrition Examination Survey (NHANES-I) [28], or for HOA progression in JoCo OA [20] between African Americans (AAs) and Caucasians, AAs have a consistently lower rate of THR utilization for treatment of HOA compared with Caucasians [29-31]. Racial differences in radiographic features of HOA have also been observed; specifically, mild axial JSN has been found more common in Caucasians than in AAs, while superior JSN, lateral osteophytes, and the presence of both acetabular and femoral osteophytes have been found more common in AAs [27]. Therefore, even though the overall frequency of progression may not differ significantly between AAs and Caucasians, disease progression may differ by race because of variations in baseline features of the disease. Our objective in this analysis was to identify baseline radiographic features that predict $\mathrm{HOA}$ progression using several different definitions, and to explore differences in these associations by race, using data from the JoCo OA.

\section{Methods \\ Data collection}

Data from the community-based JoCo OA cohort study in North Carolina were used. JoCo OA was designed to represent the civilian, non-institutionalized, AA and Caucasian population aged 45 years and older, living in one of six townships in Johnston County, NC for at least one year, and physically and mentally capable of completing the study protocol. Baseline data were collected between 1991 and 1997, with follow-up data collected between 1999 and 2003 [20, 26, 32]. From the original baseline sample of $3,187,42 \%$ were lost to follow up (Fig. 1); those that were lost to follow-up were more often AA, over 65 years of age, men, current smokers, and had less than a high school education. In addition, those who were lost to follow up reported more hip injuries at baseline, more depressive symptoms, and higher heath assessment questionnaire (HAQ) scores. There was no difference between those who remained in the study and those lost to follow up for hip OA, hip symptoms, THR, or obesity status. The sampling and methods of JoCo OA have been previously described [32]; the study has been continuously approved by the Institutional Review Boards of the University of North Carolina and the Centers for Disease Control and Prevention, and all participants provided detailed informed consent for the parent project, including use of data in other ancillary studies.

\section{Clinical features}

Body mass index (BMI) was calculated in $\mathrm{kg} / \mathrm{m}^{2}$ from height $(\mathrm{cm})$ and weight $(\mathrm{kg})$ measured during the physical examination. Age, gender, and race were selfreported. Educational attainment was included as an indicator of socioeconomic status. Symptoms were assessed separately for the right and left hips using the following question, administered by trained interviewers: 


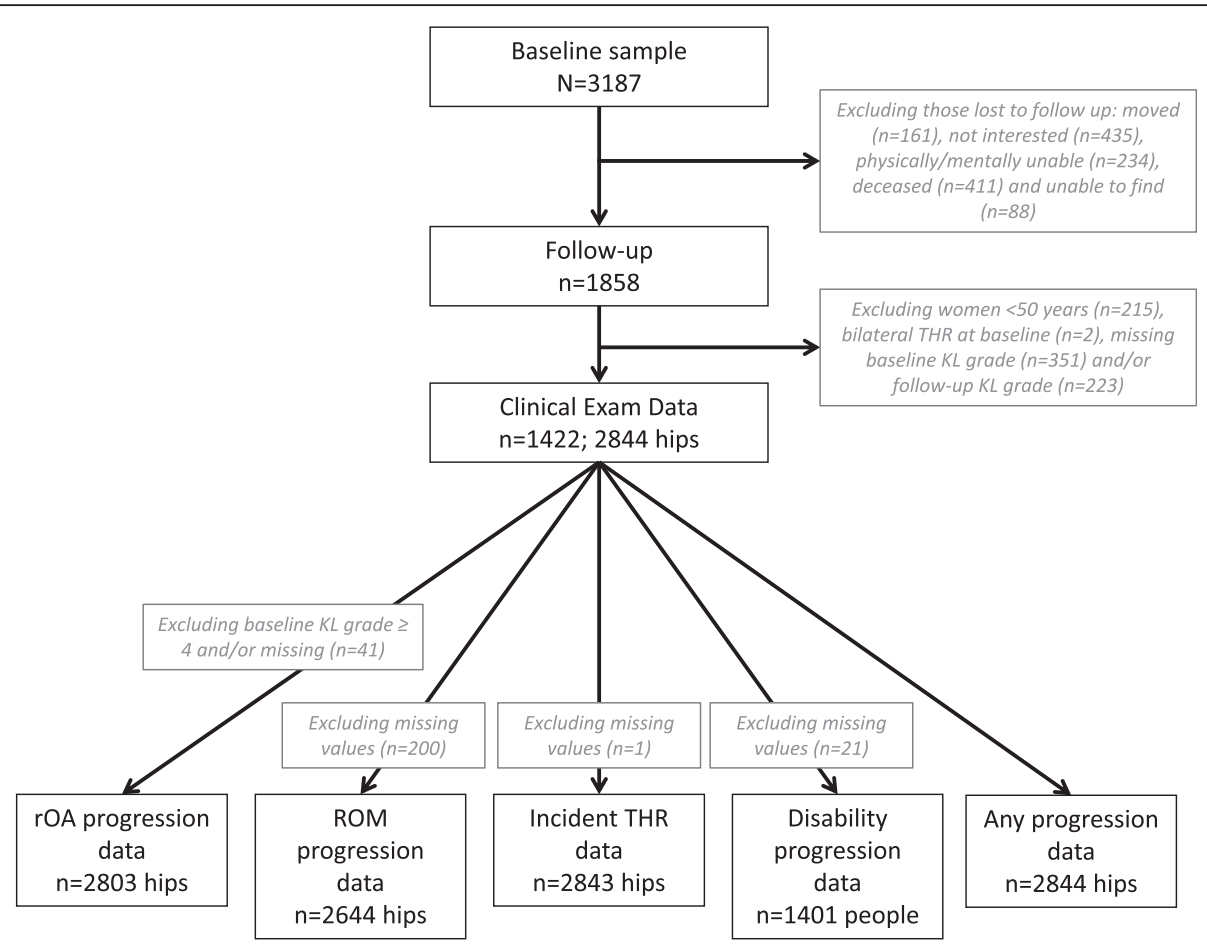

Fig. 1 Strengthening the reporting of observational studies in epidemiology (STROBE) diagram of included participants and hips for each progression outcome. THR total hip replacement, KL Kellgren-Lawrence, rOA radiographic osteoarthritis, ROM range of motion

"On most days, do you have pain, aching, or stiffness in your (right, left) hip?" [26, 32]; if answered affirmatively, participants rated these symptoms as mild, moderate, or severe. The Center for Epidemiologic Studies Depression Scale (CES-D) score was used as a measure of depressive symptoms [33]. Internal rotation in degrees was assessed for each hip using a goniometer. With the hip and knee flexed to $90^{\circ}$, the participant's foot was rotated outward, and the angle was measured and recorded to the nearest degree by trained examiners. Pain on internal rotation was also assessed and recorded as mild ("patient states that it is painful"), moderate ("patient winces"), or severe ("patient withdraws").

\section{Radiographic features}

Supine anteroposterior pelvic films, with the participant's feet in $15^{\circ}$ of internal rotation, were taken of all men, and of women $\geq 50$ years of age. Baseline and follow-up hip radiographs were read as a pair by a single musculoskeletal radiologist (JBR), without knowledge of time point or participant clinical status. The KL radiographic atlas was used to assign overall hip radiographic grades [34]. Inter-rater and intra-rater reliability for KL grades for this reader were high $(\kappa=0.859$ and 0.886 , respectively), as previously described [35]. Radiographs scored as $\mathrm{KL}$ grade 0 (no HOA) showed no radiographic features of OA; KL grade 1 (questionable HOA) showed a small osteophyte of doubtful significance. KL grade 2 radiographs (mild HOA) showed an osteophyte, but no JSN. Radiographs showing moderate JSN were given a $\mathrm{KL}$ grade 3 (moderate $\mathrm{HOA}$ ), and radiographs that included subchondral bone sclerosis and severe JSN were assigned a KL grade 4 (severe HOA) [34]. rHOA was defined as a $K L$ grade $\geq 2$. Four individual features of $\mathrm{HOA}$ were also assessed: presence of 1) JSN (superior, axial, medial or any combination of these,as defined by Lanyon et al. [36], Fig. 2); 2) subchondral cysts; 3) subchondral sclerosis; and 4) osteophytes (medial and lateral, either acetabular or femoral, or both acetabular and femoral), graded according to the Burnett atlas [37]. Reliability for identification of JSN and osteophytes was assessed separately in 60 individuals, with percentage agreement of $92 \%$ and $95 \%$, and intra-rater kappa scores of 0.82 (95\% CI $0.67,0.97)$ and $0.64(0.27,1.00)$, respectively. We were unable to analyze the severity of JSN and osteophytes due to extremely small numbers of participants with severe disease.

\section{Disability}

Self-reported functional status was assessed with the Stanford HAQ disability index [38]. Participants scored 20 activities in 8 domains from 0 (no difficulty) to 3 (unable to do), with those activities requiring assistance to complete designated as a score of 2 . The total HAQ 


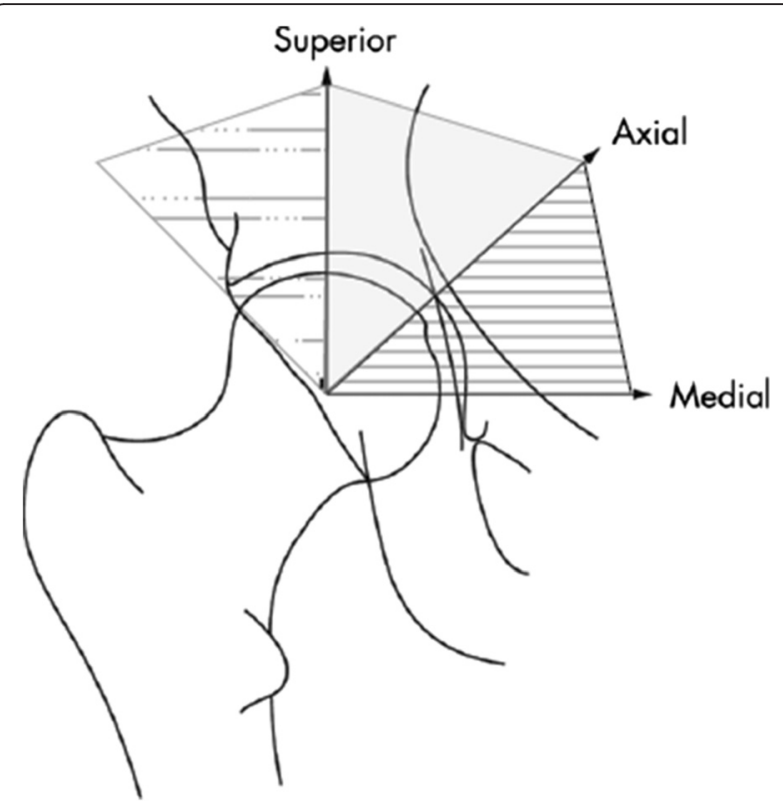

Fig. 2 Depiction of superior, axial, and medial definitions of joint space narrowing (JSN). The region shaded with dots and dashes is defined as superior JSN, the solid gray as axial JSN, and the horizontal lines as medial JSN. Figure adapted from Lanyon, et al. Ann Rheum Dis 2004;63:259-63 [36]

score was calculated by using the highest score from each domain, then averaging the 8 domains [38].

\section{Progression}

Progression was defined in four separate ways:

1) Radiographic (rHOA) progression: an increase in $\mathrm{KL}$ grade $\geq 1$ (regardless of baseline KL)

2) Range of motion (ROM) progression: a reduction in internal rotation of the hip of $\geq 10^{\circ}$ on standardized exam

3) THR progression: receipt of THR at follow up

4) Disability progression: an increase of 0.2 or more in HAQ score [38]

Or, given the variety of hip OA progression definitions in the literature, as any of the above ("Any progression"). We also considered increase in severity of hip symptoms, and an increase in pain severity with internal rotation as potential definitions of progression. We used an increase of at least one KL grade to define rHOA progression without requirement for a minimum baseline $\mathrm{KL}$ grade in order to avoid conditioning on an intermediate [39], allowing inclusion of all hips regardless of baseline KL grade and accounting for worsening of any magnitude. A novel definition of ROM progression was defined as a loss of at least $10^{\circ}$ of internal rotation, based in part on clinical experience and known associations between internal rotation mobility and HOA [40]. In addition, Hando et al. described a $10^{\circ}$ improvement in internal rotation following an 8-week physical therapy program for HOA that was also associated with a greater than minimal clinically important difference in Harris hip score [41], suggesting the clinical importance of this amount of change. This measure has been shown to be reliable [42], and was reliable at a later time point in the JoCo OA, with difference scores between two examiners $<1^{\circ}$ (in 40 random participants, difference scores were $0.21^{\circ}$ (95\% CI $\left.-0.7,1.13\right)$ on the left and $-0.94^{\circ}$ (95 \% CI $-1.64,0.24$ ) on the right; percent agreement for pain on internal rotation was also high: left 0.76 (95\% CI $0.63,0.90)$, and right 0.79 (95\% CI $0.66,0.92$ ). THR is a widely accepted hard outcome in HOA progression, and disability progression was defined using an accepted cutoff for clinically meaningful worsening in HAQ score [38].

\section{Statistical analysis}

Descriptive statistics were calculated to characterize the population for all variables of interest, including baseline demographics, baseline hip radiographic features, and HOA progression measures. Continuous variables were described using means with standard deviation (SD); categorical data were described using percentages.

Prevalent HOA measures were evaluated based on status at baseline, and progression was evaluated as the change from baseline to follow up. For the outcomes of pain increase and KL increase, individuals who had a prevalent highest level of pain (severe), or KL grade $(\mathrm{KL}=4)$, respectively, at baseline were excluded because they were not eligible for progression of these measures. Analyses also excluded individuals who had both hips replaced at baseline, hips with THR at baseline, and hips missing baseline or follow up KL grades. Women under the age of 50 were also excluded because to avoid pelvic radiation they did not undergo hip radiography (Fig. 1).

With the exception of disability progression, all OA progression measures used were specific to each hip, and all analyses were based on the individual hip as the unit of analysis. We used generalized estimating equations (GEE) to address the potential correlation between right and left hip measurements within one person. We used logistic regression analysis to estimate odds ratios (OR) and $95 \% \mathrm{CI}$ for the strength of association between dichotomous baseline hip radiographic features and dichotomous OA progression. All models were adjusted for age, gender, race, prior hip injury, BMI (categorical data were used, although use of continuous BMI data did not affect the results), education, smoking and follow-up time. Analyses of rHOA progression were additionally adjusted for baseline KL grade, while 
analyses of disability progression were additionally adjusted for baseline CES-D scores. Bonferroni-adjusted alpha was set at $p<0.013$ for JSN predictors and $p<0.006$ for osteophyte predictors. Additional analyses were carried out to assess for interaction by race, and where significant interactions were identified $(p \leq 0.1)$, stratified analyses were performed. All statistical analyses were completed using SAS version 9.2 (SAS Institute Inc., Cary, NC, USA).

\section{Results}

\section{Baseline characteristics}

Baseline and follow-up data were available for 1,422 participants (Table 1, Fig. 1). The average age of the study group was $61.4 \pm 9$ years; $40 \%$ were men and $26 \%$ were AA. The majority of study participants were overweight or obese. One third of participants had not completed high school. The average time to follow up was $6.0 \pm 1.4$ years. Eight percent of participants met the criteria for at least mild depression, defined as a CES-D score $>16$ [33]. Mean HAQ score at baseline was $0.3 \pm 0.5$. AAs were more likely to be heavier, female, report less education beyond high school, currently smoke, and to have had longer times to first follow up.

As shown in Table 2, at baseline, $23 \%$ of participants had definite rHOA ranging from mild to severe

Table 1 Demographic and clinical characteristics of baseline study participants

\begin{tabular}{|c|c|c|c|c|}
\hline & All participants & Caucasian & AA & $P$ value \\
\hline $\begin{array}{l}\text { Baseline demographic } \\
\text { characteristics }\end{array}$ & $n=1422$ & $n=1054$ & $n=368$ & \\
\hline Age, mean (SD), years & $61.4(9.0)$ & $61.4(8.8)$ & $61.5(9.4)$ & 0.6967 \\
\hline BMl, mean (SD), kg/m² & $28.9(5.4)$ & $28.3(4.9)$ & $30.6(6.2)$ & $<0.0001$ \\
\hline$<25 \%$ & 23.1 & 26.3 & 14.0 & $<0.0001$ \\
\hline $25-<30 \%$ & 41.3 & 41.6 & 40.7 & \\
\hline $30+\%$ & 35.5 & 32.2 & 45.3 & \\
\hline Gender, \% women & 60.0 & 56.8 & 69.0 & $<0.0001$ \\
\hline $\begin{array}{l}\text { Educational attainment } \\
<\mathrm{HS}, \%\end{array}$ & 33.0 & 28.3 & 46.3 & $<0.0001$ \\
\hline \multicolumn{5}{|l|}{ Smoking } \\
\hline Never \% & 51.2 & 49.4 & 56.3 & $<0.0001$ \\
\hline Past \% & 32.0 & 35.2 & 22.8 & \\
\hline Current \% & 16.8 & 15.4 & 20.9 & \\
\hline Hip injury, \% & 2.4 & 2.3 & 2.6 & 0.5723 \\
\hline CES-D $<16, \%$ & 8.0 & 7.4 & 9.9 & 0.0315 \\
\hline $\mathrm{HAQ}$, mean $(\mathrm{SD})$, score & $0.3(0.5)$ & $0.3(0.5)$ & $0.3(0.5)$ & 0.1992 \\
\hline $\begin{array}{l}\text { Follow-up time, } \\
\text { mean (SD), years }\end{array}$ & $6.0(1.4)$ & $5.8(1.3)$ & $6.5(1.4)$ & $<0.0001$ \\
\hline
\end{tabular}

AA African American, $B M I$ body mass index, HS high school, CES-D Center for Epidemiologic Studies depression scale, HAQ health assessment questionnaire
Table 2 Hip features of study participants at baseline

\begin{tabular}{lllll}
\hline Hip radiographic feature & All participants & Caucasian & AA & $P^{a}$ \\
at baseline & $n=1422$ & $n=1054$ & $n=368$ &
\end{tabular}

\section{$\mathrm{KL}$ grade}

$\begin{array}{llll}\text { 0: No hip OA \% } & 15.3 & 17.3 & 9.5 \\ \text { 1: Questionable hip OA \% } & 61.6 & 59.3 & 68.5 \\ \text { 2: Mild hip OA \% } & 21.6 & 22.2 & 19.7 \\ \text { 3: Moderate hip OA \% } & 1.3 & 1.1 & 1.9 \\ \text { 4: Severe hip OA \% } & 0.2 & 0.1 & 0.4\end{array}$

JSN

Axial

$\begin{array}{lll}\text { None } \% & 77.7 & 75.9\end{array}$

$<0.0001$

Mild \% 21.6

Moderate/severe \% $\quad 0.7$

0.7

23.7

15.7

Superior

None \%

Mild \%

Moderate/severe \% 0.6

Medial

None \%

Mild \%

Moderate/severe \%

Subchondral

Cysts \%

Sclerosis \%

Medial osteophytes

Severity

None \%

Mild \%

Moderate/severe \%

Location

None \%

Acetabular only \%

Femoral only $\%$

Both \%

0.1

98.2

98.

$0.8599^{\mathrm{b}}$

$\begin{array}{ll}1.7 & 1.9\end{array}$

$0.1 \quad 0$

Lateral osteophytes

Severity

$\begin{array}{lllll}\text { None \% } & 42.8 & 46.0 & 33.9 & <0.0001 \\
\text { Mild \% } & 48.6 & 46.5 & 54.6 & \\
\text { Moderate/severe \% } & 8.5 & 7.5 & 11.4 & \\
\text { Location } & & & & \\
\text { None \% } & 42.8 & 46.0 & 33.7 & <0.0001 \\
\text { Acetabular only \% } & 40.8 & 38.2 & 48.1 & \\
\text { Femoral only \% } & 4.7 & 5.1 & 3.6 & \\
\text { Both \% } & 11.7 & 10.7 & 14.7 & \end{array}$

${ }^{a}$ Chi-square or Fisher's Exact p-value comparing Caucasians to African Americans $(A A s) .{ }^{\text {b }}$ Fisher's exact test $p$ value. $K L$ Kellgren-Lawrence, $O A$ osteoarthritis, JSN joint space narrowing 
(KL grade 2-4). At baseline, axial JSN (Fig. 2) was most frequent, while medial JSN was least frequent. Subchondral sclerosis was seen more frequently than subchondral cysts. Osteophytes were observed on the femoral and acetabular sides of the joint, both laterally and medially; lateral acetabular osteophytes were most common (Table 2).

\section{Racial differences at baseline}

Racial differences were noted at baseline (Table 2). While the prevalence of definite rHOA was similar between AA and Caucasian participants, AAs were more likely to have a KL grade of 1 , and significantly less likely to have a KL grade of 0 compared with Caucasians. Axial JSN was significantly more common in Caucasian compared with AA participants, while superior JSN was more common in AAs. No significant racial difference was seen for medial JSN, subchondral bone changes, or medial osteophytes, but AAs were more likely to have lateral osteophytes (Table 2).

\section{Follow-up characteristics}

At follow up, $15 \%$ of hips had undergone rHOA progression, including $16 \%$ of hips in Caucasians and $11 \%$ of hips in AAs $(p=0.0007$, Table 3). Progression occurred in $15 \%$ of hips according to the ROM definition; $14 \%$ of hips in Caucasians, and $19 \%$ of hips in AAs $(p=0.0012)$. Twelve individuals had undergone THR with no significant difference by race $(p=0.742)$. Compared with Caucasians, AAs were more likely to have a higher frequency of any progression (55\% vs. $48 \%$, respectively), and to have an increase of at least 0.2 points in HAQ score ( $40 \%$ vs. $29 \%$, respectively, $p$ <0.0001). Overlap between these definitions is depicted in the Venn diagram in Fig. 3.

\section{Associations with progression Joint space narrowing}

Those with JSN at any site (axial, medial or superior, Table 4) were almost three times as likely to have rHOA progression, $30 \%$ more likely to have ROM progression, and thirteen times as likely to have received a THR at follow up. JSN was not associated with disability progression, and was modestly associated with any progression. After correction for multiple comparisons, the association between JSN at any site and rHOA progression $(p<0.0001)$ was still statistically significant, but association with ROM progression and THR was not. JSN at any site was associated with disability progression in AAs (adjusted OR (Aor) =1.71, 95 \% CI (1.06, 2.74 ), interaction $p$ value $=0.037$ ) but not in Caucasians (aOR 0.92, 95 \% CI $(0.68,1.23)$ ); no interactions were seen for other progression outcomes and JSN.

By location, axial JSN was positively associated with rHOA and ROM progression in adjusted analyses. Axial JSN was also associated with THR, but with a very wide CI. There were no associations between axial JSN and disability or any progression. Using Bonferroni-adjusted $p$ values for multiple comparisons, the association between axial JSN and RHOA progression $(p=0.0001)$ was still statistically significant, but those with ROM progression and THR were not (Table 4). Superior JSN was associated with rHOA progression, disability progression, and any progression. There were no statistically significant associations between superior JSN and ROM progression or THR. After adjustment for multiple comparisons, the associations found between superior JSN and rHOA progression $(p<0.0001)$ was still statistically significant, but the association with disability progression and any progression were not. Medial JSN, though infrequent in the sample, was the most strongly associated with rHOA progression and with THR. There was no association between medial JSN and ROM progression, disability progression, or any progression. After correction for multiple comparisons, only the association between THR and medial JSN $(p<0.0001)$ was still statistically significant.

\section{Subchondral bone changes}

Subchondral cysts were associated only with rHOA progression $(\mathrm{aOR}=1.83,95 \% \mathrm{CI}(1.01,3.31))$, but this association was no longer significant after adjustment for

Table 3 Hip OA progression by individual definitions

\begin{tabular}{|c|c|c|c|c|}
\hline \multirow[t]{2}{*}{ OA progression indicators } & All participants & Caucasian & AA & \multirow[t]{2}{*}{$P^{a}$} \\
\hline & n (\%) & n (\%) & $n(\%)$ & \\
\hline Radiographic OA progression ${ }^{\mathrm{b}}(\mathrm{n}=2,803$ hips) & $411(14.7)$ & $332(16.0)$ & $79(10.8)$ & 0.0007 \\
\hline Range of motion progression ${ }^{c}(n=2,644$ hips) & $404(15.3)$ & $279(14.0)$ & $125(19.3)$ & 0.0012 \\
\hline Incident hip replacement at T1 ( $\mathrm{n}=2,843$ hips) & $12(0.4)$ & $10(0.5)$ & $2(0.3)$ & $0.742^{d}$ \\
\hline Disability progression $^{\mathrm{e}}(\mathrm{n}=1,401$ participants) & $445(31.8)$ & $302(29.0)$ & $143(39.7)$ & $<0.0001$ \\
\hline Any progression ( $n=2844$ hips) & $1,406(49.4)$ & $1,003(47.6)$ & $403(54.8)$ & 0.0008 \\
\hline
\end{tabular}

${ }^{a}$ Chi-square or Fisher's exact test $p$ value comparing Caucasians to African Americans (AA). ${ }^{b}$ Kellgren-Lawrence grade increased by at least 1 from time point 0 (T0)

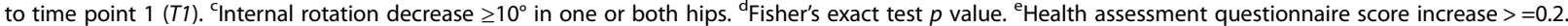
OA osteoarthritis 


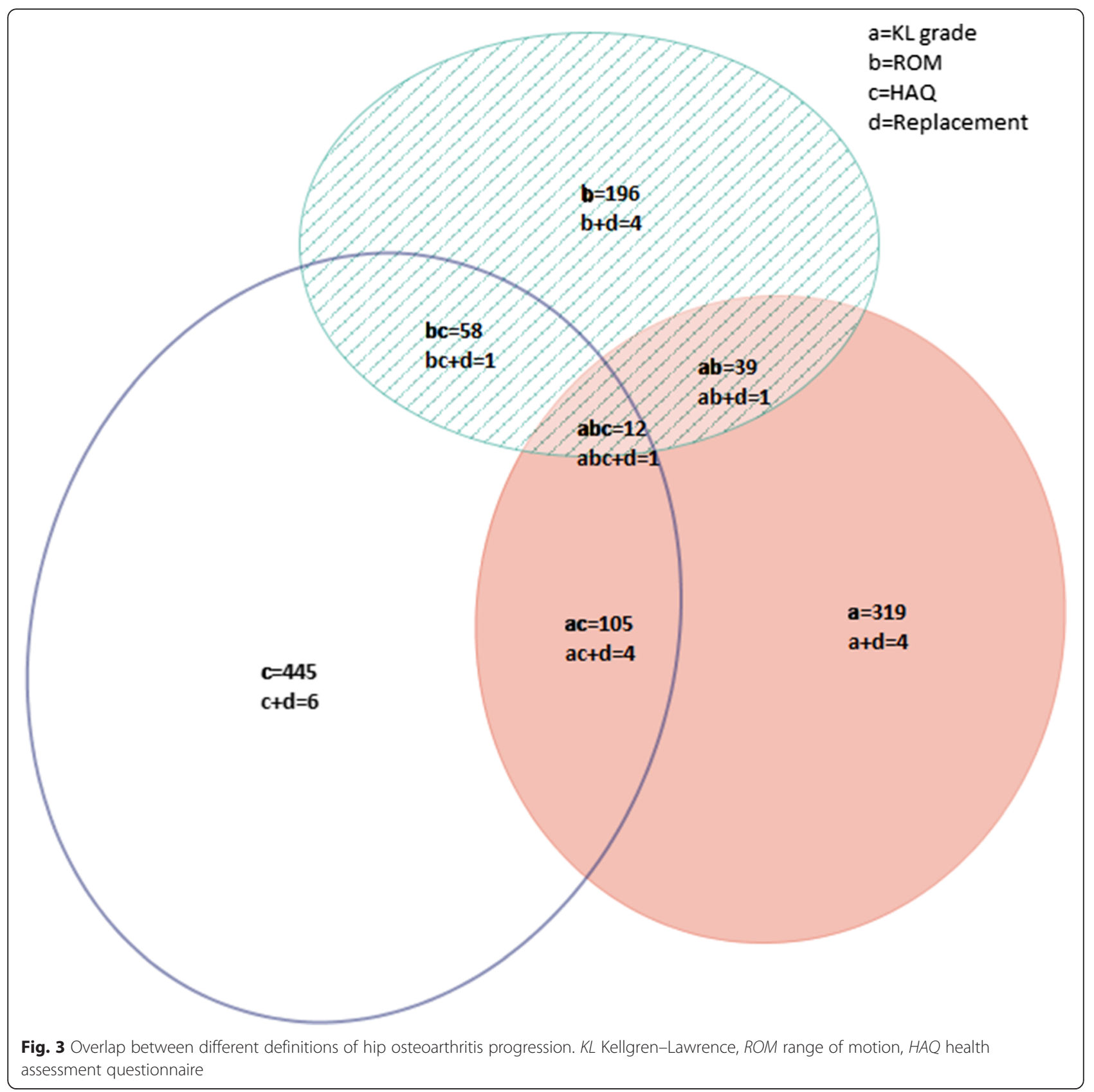

multiple comparisons. Subchondral sclerosis was associated with rHOA progression $(\mathrm{aOR}=2.09,95 \% \mathrm{CI}$ $(1.4,-3.03))$ and with THR $(\mathrm{aOR}=5.95,95 \% \mathrm{CI}(1.78$, 19.9)), but no associations were seen with ROM, disability, or any progression. Using Bonferroni-adjusted $p$ values for multiple comparisons, the association between subchondral sclerosis with rHOA progression and THR was still statistically significant $(p=0.0001$ and $p=0.0038$, respectively). There was a stronger association between subchondral sclerosis and rHOA progression in AAs (aOR 3.64, $95 \% \mathrm{CI}(1.61,8.21))$ than in Caucasians $(\mathrm{aOR}=1.81,95 \%$ CI $(1.19,2.75)$, interaction $p$ value $=0.069)$; no interactions were seen for other progression outcomes and subchondral changes.

\section{Osteophytes}

Those with osteophytes at any site (medial, lateral, acetabular, femoral) had $50 \%$ higher odds of ROM progression, and $16 \%$ lower odds of any progression (Table 5). Those with any medial osteophytes were three times as likely to have rHOA progression, seventeen times as likely to have THR, and $40 \%$ more likely to have any progression. Medial acetabular osteophytes were associated with rHOA progression, ROM progression, and 
Table 4 Adjusted odds ratios (aORs) for associations between patterns of JSN and progression

\begin{tabular}{llllll}
\hline JSN & $\begin{array}{l}\text { rOA progression } \\
(\mathrm{n}=411 \text { hips })\end{array}$ & $\begin{array}{l}\text { ROM progression } \\
(\mathrm{n}=404 \text { hips })\end{array}$ & $\begin{array}{l}\text { THR } \\
(\mathrm{n}=12 \mathrm{hips})\end{array}$ & $\begin{array}{l}\text { Disability progression } \\
(\mathrm{n}=445 \text { participants })\end{array}$ & $\begin{array}{l}\text { Any progression } \\
(\mathrm{n}=1406 \text { participants })\end{array}$ \\
\hline Any location & $2.62(1.95,3.51)^{\mathrm{a}}$ & $1.31(1.05,1.63)$ & $12.9(1.63,102)$ & $1.06\left(0.83,1.36^{\mathrm{b}}\right.$ & $1.20(1.03,1.40)$ \\
Axial & $2.05(1.44,2.91)^{\mathrm{a}}$ & $1.30(1.00,1.68)$ & $19.9(2.50,159)$ & $0.86(0.66,1.12)$ & $1.11(0.92,1.33)$ \\
Superior & $2.75(1.79,4.24)^{\mathrm{a}}$ & $1.11(0.81,1.53)$ & $1.78(0.45,6.99)$ & $1.50(1.07,2.09)$ & $1.42(1.11,1.82)$ \\
Medial & $4.51(1.47,13.8)$ & $0.68(0.33,1.40)$ & $39.2(7.91,194)^{\mathrm{a}}$ & $1.40(0.69,2.88)$ & $1.56(0.76,3.21)$ \\
\hline
\end{tabular}

All models were adjusted for age, gender, race, prior hip injury, body mass index, education, smoking and follow-up time; the progression of radiographic osteoarthritis ( $\mathrm{rOA}$ ) outcome was additionally adjusted for baseline Kellgren-Lawrence grade, while the disability outcome was also adjusted for the Center for Epidemiologic Studies Depression Scale. ${ }^{\mathrm{a} S}$ Statistically significant after Bonferroni adjustment of $p$ values. ${ }^{\mathrm{b}}$ Significant interaction ( $p=0.037$ ) by race: for African Americans the $\mathrm{aOR}=1.71,95 \% \mathrm{Cl}(1.06,2.74)$, for Caucasians the aOR $=0.92,95 \% \mathrm{Cl}(0.68,1.23)$. JSN joint space narrowing, ROM range of motion, THR total hip replacement

THR but not with disability or any progression. Medial femoral osteophytes were associated only with rHOA progression and THR. The combination of both medial acetabular and femoral osteophytes was associated with THR but was protective against ROM progression. Using Bonferroni-adjusted $p$ values for multiple comparisons, the associations between rHOA progression and any medial osteophytes $(p<0.0001)$, and medial femoral osteophytes $(p=0.0005)$ remained statistically significant. Additionally, the associations of any medial osteophytes or any femoral osteophytes, or both with THR $(p<0.0001)$ remained statistically significant after correction for multiple comparisons.

Those with any lateral osteophytes were $40 \%$ more likely to have ROM progression, but were $18 \%$ less likely to have any progression. The presence of lateral acetabular osteophytes was associated with ROM progression, while lateral femoral osteophytes were associated with rHOA progression and THR at follow up. The presence of lateral osteophytes on both the acetabular and femoral sides was associated with rHOA progression and THR but no other progression definitions. Using Bonferroni-adjusted $p$ values for multiple comparisons, the association between the presence of lateral acetabular osteophytes and ROM progression was still statistically significant, but other associations were not.

The presence of lateral osteophytes was associated with $\mathrm{ROM}$ progression in Caucasians $(\mathrm{aOR}=1.65,95 \%$ CI $(1.25,2.17)$, interaction $p$ value $=0.038)$ but not in AAs (aOR 0.99, 95 \% CI $(0.64,1.53))$. Similar associations were seen for lateral acetabular osteophytes. Lateral femoral osteophytes were potentially protective against ROM progression in AAs, but not in Caucasians

Table 5 Adjusted odds ratios (aORs) for associations between patterns of osteophytes and progression

\begin{tabular}{|c|c|c|c|c|c|}
\hline Osteophytes & $\begin{array}{l}\text { rOA progression } \\
(n=411 \text { hips })\end{array}$ & $\begin{array}{l}\text { ROM progression } \\
(n=404 \text { hips) }\end{array}$ & $\begin{array}{l}\text { THR } \\
(\mathrm{n}=12 \text { hips })\end{array}$ & $\begin{array}{l}\text { Disability progression } \\
\text { ( } n=445 \text { participants) }\end{array}$ & $\begin{array}{l}\text { Any progression } \\
\text { ( } n=1406 \text { participants) }\end{array}$ \\
\hline Any site & $0.99(0.77,1.29)$ & $1.51(1.19,1.92)^{*}$ & $1.87(0.40,8.83)$ & $1.05(0.81,1.36)$ & $0.84(0.72,0.97)$ \\
\hline \multicolumn{6}{|l|}{ Medial } \\
\hline Any site & $2.99(1.93,4.64)^{*}$ & $1.27(0.89,1.81)$ & $17.4(4.80,63.1)^{*}$ & $1.28(0.89,1.84)$ & $1.39(1.05,1.83)$ \\
\hline Any acetabular & $2.80(1.34,5.83)$ & $1.58(1.04,2.42)$ & $5.33(1.01,28.1)$ & $1.39(0.78,2.50)$ & $1.40(0.98,2.02)$ \\
\hline Any femoral & $2.63(1.52,4.54)^{*}$ & $0.72(0.46,1.12)$ & $13.5(3.23,56.5)^{*}$ & $1.66(0.96,2.85)$ & $1.19(0.85,1.68)$ \\
\hline Both acetabular and femoral & $2.55(0.52,12.6)$ & $0.41(0.20,0.84)$ & $30.3(4.25,216)^{*}$ & $1.40(0.51,3.85)$ & $0.97(0.49,1.95)$ \\
\hline \multicolumn{6}{|l|}{ Lateral } \\
\hline Any site & $0.95(0.73,1.23)$ & $1.40(1.11,1.77)^{\text {ta }}$ & $1.15(0.30,4.44)$ & $1.04(0.80,1.34)$ & $0.82(0.71,0.95)$ \\
\hline Any acetabular & $0.94(0.71,1.24)$ & $1.45(1.15,1.84)^{*}+b$ & $1.67(0.48,5.78)$ & $0.99(0.78,1.26)$ & $0.84(0.71,1.00)$ \\
\hline Any femoral & $1.43(1.03,1.97)$ & $0.95(0.72,1.26)^{\dagger c}$ & $4.09(1.28,13.1)$ & $1.18(0.88,1.58)$ & $1.11(0.92,1.33)^{t d}$ \\
\hline Both acetabular and femoral & $1.65(1.12,2.41)$ & $1.00(0.71,1.39)$ & $4.08(1.24,13.4)$ & $1.19(0.85,1.67)$ & $1.21(0.97,1.50)^{\mathrm{te}}$ \\
\hline
\end{tabular}

All models adjusted for age, gender, race, prior hip injury, body mass index, education, smoking and follow-up time; the radiographic osteoarthritis ( $r O A$ ) outcome was additionally adjusted for baseline Kellgren-Lawrence grade, while the disability outcome was adjusted also for the Center for Epidemiologic Studies depression scale. * ${ }^{*}$ tatistically significant after Bonferroni $p$ value adjustment. ${ }^{\dagger}$ Significant interactions by race. ${ }^{\text {ta }}$ For $\mathrm{AAs}$ aOR $=0.99,95 \% \mathrm{Cl}(0.64,1.53)$, for Caucasians aOR $1.65,95 \% \mathrm{Cl}(1.25,2.17)$, interaction $p=0.038$. ${ }^{\mathrm{tb}} \mathrm{For} \mathrm{AAs}$ aOR $=1.10,95 \% \mathrm{Cl}(0.72,1.68)$, for Caucasians aOR $=1.65,95 \% \mathrm{Cl}(1.25,2.19)$, interaction $p=0.091$. ${ }^{\mathrm{tc}} \mathrm{For}$ $\mathrm{AAs} \mathrm{aOR}=0.58,95 \% \mathrm{Cl}(0.34,0.98)$, for Caucasians aOR $=1.16,95 \% \mathrm{Cl}(0.83,1.61)$, interaction $p=0.015$. ${ }^{\mathrm{dd}} \mathrm{For} \mathrm{AAs}$ aOR $=0.83,95 \% \mathrm{Cl}(0.58,1.19)$, for Caucasians $\mathrm{aOR}=1.23,95 \% \mathrm{Cl}(0.99,1.52)$, interaction $p=0.056 .{ }^{\text {te }}$ For $\mathrm{AAs}$ aOR $=0.87,95 \% \mathrm{Cl}(0.59,1.28)$, for Caucasians aOR $=1.33,95 \% \mathrm{Cl}(1.01,1.76)$, interaction $p=0.067$ $R O M$ range of motion, THR total hip replacement 
at follow up (AA aOR $=0.58,95 \%$ CI $(0.34,0.98)$, Caucasian $\mathrm{aOR}=1.16,95 \% \mathrm{CI}(0.83,1.61)$, interaction $p$ value $=0.015$ ), and were associated with any progression in Caucasians only (AA aOR $=0.83,95 \% \mathrm{CI}$ (0.58, 1.19), Caucasian aOR $=1.23$, 95 \% CI $(0.99,1.52)$, interaction $p$ value $=0.056$ ). The combination of acetabular and femoral osteophytes together was also associated with any progression only in Caucasians (AA aOR $=0.87$, $95 \%$ CI $(0.59,1.28)$, Caucasian $\mathrm{aOR}=1.33,95 \% \mathrm{CI}(1.01$, 1.76 ), interaction $p$ value $=0.067$ )

There were no associations between any of the radiographic features and either increased hip symptoms or increased pain on internal rotation (data not shown).

\section{Discussion}

All investigated radiographic features were associated with at least one of the four HOA progression definitions; JSN, bony sclerosis, and osteophytes were all associated with multiple progression outcomes.

\section{Baseline racial differences}

Our group previously identified racial differences in radiographic features using cross-sectional baseline JoCo OA data. Specifically, there was a higher frequency of mild axial JSN in Caucasians, superior JSN in AAs, and higher frequency of lateral osteophytes in AAs [27]. The current study confirms these findings in a sample restricted to 1,422 study participants who had paired radiographic readings for baseline and follow up.

\section{Association with progression: JSN}

Several studies have identified positive associations between quantitative joint space width (JSW) at baseline and HOA progression at follow up defined as JSN or THR [8-10, 18, 43]. These studies did not differentiate between axial, superior, and medial narrowing. We identified differences in associations with progression outcomes based on patterns of JSN such that axial JSN was associated with rHOA and ROM progression, but superior JSN was associated with rHOA and disability progression. Because only a small number of hips were replaced, the observed associations between JSN and THR had very wide confidence intervals and are likely unstable; this notwithstanding, associations between axial and medial JSN and THR were very strong. Lane et al., using data from the Study of Osteoporotic Fractures (SOF), reported associations between superolateral JSN (comparable to superior JSN in our study) and THR or a decrease of at least $0.5 \mathrm{~mm}$ in minimum JSW; superomedial JSN (comparable to axial JSN) was associated with increased risk of THR but appeared to be protective against an increase in summary OA grade or increase in osteophyte score [13]. Differences in the two studies may reflect differences in follow-up time
(8 years for SOF, 6 years for JoCo OA), population (Caucasian women in SOF versus AA and Caucasian men and women in the current study), grading scheme (Croft versus KL) and age (mean 72 years for SOF and 61 years for JoCo OA). Additionally, the SOF examined only the 745 women who had rHOA at baseline for progression, while in the current study we included all 1,422 participants with paired films, therefore likely capturing earlier stages of incident and progressive HOA.

\section{Associations with progression: osteophytes and subchondral changes}

Previous studies have identified positive associations between osteophytes and progression (defined as JSN, THR, composite definitions, or increase in $\mathrm{KL}$ grade) $[10,13,23]$. We found positive associations between medial acetabular osteophytes and both rHOA and ROM progression. Lateral acetabular osteophytes, which may lead to pincer impingement $[44,45]$, were also associated with ROM progression. We found positive associations between lateral femoral osteophytes and rHOA progression and THR. Medial femoral osteophytes were also associated with rHOA progression. Association was reported between femoral osteophytes and all progression outcomes assessed in the SOF, while acetabular osteophytes were not statistically significantly associated with progression by any definition [13]. Osteophytes in that study, however, were not differentiated by medial or lateral location. Like Lane et al., we found associations between cysts and sclerosis and rHOA progression.

\section{Racial differences}

In this follow up to our 2010 cross-sectional analysis [27], we were interested in determining the impact of racial differences in radiographic features at baseline in this population on the course of hip OA after approximately 6 years of follow up. Given the higher frequency of osteophytosis and superior JSN in AAs, which had previously been associated with increased THR utilization in another study [13], we hypothesized that AAs might have a higher risk of progression compared with Caucasians. In the current study, although AAs were again noted to have a similar prevalence of RHOA compared with Caucasians, AAs had less rHOA progression, but more frequent disability and ROM progression. Therefore, indications for THR in this group may be more related to alterations in physical function and disability rather than progressive radiographic change. There are complex and multifactorial issues surrounding disparities in THR utilization that also affect this issue and are well-reviewed in the literature [46-49].

This study had several limitations, including a small sample size for THR outcomes $(<1 \%$ had undergone THR at follow up) leading to wide confidence intervals 
for these estimates. We did not have continuously measured quantitative joint space width, but did have semiquantitative measures of JSN available. Our study also has many strengths. This large cohort included both AA and Caucasian men and women and was communitybased. The data are from standardized questionnaires, physical examinations of clinically relevant outcomes with high reliability, and paired radiographs, including detailed radiographic features with high reliability from a single musculoskeletal radiologist. This study, in comparison to prior work, included a more in-depth analysis of the location of osteophytes and JSN in regards to HOA progression and assessed multiple definitions of progression including radiographic and clinical features.

\section{Conclusions}

AAs and Caucasians exhibited differences in baseline hip radiographic features with implications for HOA progression. AAs reported increased pain and disability after 6 years of follow up, while Caucasians had more rHOA progression. Worsening of disability in association with baseline radiographic features in AAs is supportive of a potential unmet need for hip OA management in this population.

\begin{abstract}
Abbreviations
AA: African American; aOR: adjusted odds ratio; BMI: body mass index; CES-D: Center for Epidemiologic Studies depression scale; HAQ: health assessment questionnaire; HOA: hip osteoarthritis; JoCo OA: Johnston County Osteoarthritis Project; JSN: joint space narrowing; KL: KellgrenLawrence; OA: osteoarthritis; OR: odds ratio; rHOA: radiographic hip osteoarthritis; ROM: range of motion; SOF: Study of Osteoporotic Fractures; THR: total hip replacement.
\end{abstract}

\section{Competing interests}

The authors declare that they have no competing interests.

\section{Authors' contributions}

Conception and design: AEN, JMJ. Acquisition of data: JBR, JMJ. Analysis and interpretation of data: BF, RJC, JBR, JMJ, AEN. Drafting the manuscript: BF, AEN. Critical revision of the manuscript for important intellectual content: RJC, JBR, JMJ, AEN. Final approval of the version to be submitted: BF, RJC, $J B R, J M J$, and AEN.

\section{Acknowledgements}

We would like to thank the staff and participants in the Johnston County Osteoarthritis Project, without whom this work would not have been possible. This work was funded in part by: Foley: American Geriatrics Society Medical Student Training in Aging Research (MSTAR) program and American College of Rheumatology/Rheumatology Research Foundation Medical Student Research Preceptorship; Jordan/Renner: CDC/ASPH S043 and S3486, NIH/NIAMS MCRC P60 AR49465; Nelson: NIH/NIAMS K23 AR061406. The funding sources had no role in the design, analysis, manuscript preparation, or decision to submit for publication.

\section{Author details}

'University of New England College of Osteopathic Medicine, Biddeford, ME, USA. ${ }^{2}$ Thurston Arthritis Research Center, University of North Carolina at Chapel Hill, 3300 Doc J. Thurston Bldg, CB \#7280, Chapel Hill, NC 27599-7280, USA. ${ }^{3}$ Department of Medicine, University of North Carolina at Chapel Hill School of Medicine, 3300 Doc J. Thurston Bldg, CB \#7280, Chapel Hill, NC 27599-7280, USA. ${ }^{4}$ Department of Radiology, University of North Carolina at Chapel Hill School of Medicine, Chapel Hill, NC, USA. ${ }^{5}$ Department of Epidemiology, Gillings School of Global Public Health, University of North
Carolina at Chapel Hill, Chapel Hill, NC, USA. 'Department of Orthopaedics, University of North Carolina at Chapel Hill School of Medicine, Chapel Hill, NC, USA.

Received: 15 May 2015 Accepted: 28 September 2015

Published online: 18 December 2015

\section{References}

1. Pereira D, Peleteiro B, Araujo J, Branco J, Santos RA, Ramos E. The effect of osteoarthritis definition on prevalence and incidence estimates: a systematic review. Osteoarthritis Cartilage. 2011:19(11):1270-85.

2. Hootman JM, Helmick CG. Projections of US prevalence of arthritis and associated activity limitations. Arthritis Rheum. 2006;54(1):226-9.

3. Felson DT, Lawrence RC, Dieppe PA, Hirsch R, Helmick CG, Jordan JM, et al. Osteoarthritis: new insights. Part 1: the disease and its risk factors. Ann Intern Med. 2000;133(8):635-46.

4. Lawrence RC, Felson DT, Helmick CG, Arnold LM, Choi H, Deyo RA, et al. Estimates of the prevalence of arthritis and other rheumatic conditions in the United States. Part II Arthritis Rheum. 2008;58(1):26-35.

5. Salaffi F, Carotti M, Stancati A, Grassi W. Health-related quality of life in older adults with symptomatic hip and knee osteoarthritis: a comparison with matched healthy controls. Aging Clin Exp Res. 2005;17(4):255-63.

6. Katz JN, Phillips CB, Baron JA, Fossel AH, Mahomed NN, Barrett J, et al. Association of hospital and surgeon volume of total hip replacement with functional status and satisfaction three years following surgery. Arthritis Rheum. 2003:48(2):560-8.

7. Arden NK, Lane NE, Parimi N, Javaid KM, Lui LY, Hochberg MC, et al. Defining incident radiographic hip osteoarthritis for epidemiologic studies in women. Arthritis Rheum. 2009:60(4):1052-9.

8. Mazieres B, Garnero P, Gueguen A, Abbal M, Berdah L, Lequesne M, et al. Molecular markers of cartilage breakdown and synovitis at baseline as predictors of structural progression of hip osteoarthritis. The ECHODIAH. Cohort Ann Rheum Dis. 2006;65(3):354.

9. Dougados M, Gueguen A, Nguyen M, Berdah L, Lequesne M, Mazieres B, et al. Radiographic features predictive of radiographic progression of hip osteoarthritis. Rev Rhum Engl Ed. 1997;64(12):795-803.

10. Dougados M, Gueguen A, Nguyen M, Berdah L, Lequesne M, Mazieres B, et al. Radiological progression of hip osteoarthritis: definition, risk factors and correlations with clinical status. Ann Rheum Dis. 1996;55(6):356-62.

11. Beattie MS, Lane NE, Hung YY, Nevitt MC. Association of statin use and development and progression of hip osteoarthritis in elderly women. J Rheumatol. 2005;32(1):106-10.

12. Chaganti RK, Kelman A, Lui L, Yao W, Javaid MK, Bauer D, et al. Change in serum measurements of cartilage oligomeric matrix protein and association with the development and worsening of radiographic hip osteoarthritis. Osteoarthritis Cartilage. 2008;16(5):566-71

13. Lane NE, Nevitt MC, Hochberg MC, Hung YY, Palermo L. Progression of radiographic hip osteoarthritis over eight years in a community sample of elderly white women. Arthritis Rheum. 2004;50(5):1477-86.

14. Kelman A, Lui L, Yao W, Krumme A, Nevitt M, Lane NE. Association of higher levels of serum cartilage oligomeric matrix protein and $\mathrm{N}$-telopeptide crosslinks with the development of radiographic hip osteoarthritis in elderly women. Arthritis Rheum. 2006;54(1):236-43.

15. Lane NE, Nevitt MC, Lui LY, de Leon P, Corr M, Study of Osteoporotic Fractures Research $\mathrm{G}$. Wnt signaling antagonists are potential prognostic biomarkers for the progression of radiographic hip osteoarthritis in elderly Caucasian women. Arthritis Rheum. 2007;56(10):3319-25.

16. Reijman M, Bierma-Zeinstra SM, Pols HA, Koes BW, Stricker BH, Hazes JM. Is there an association between the use of different types of nonsteroidal antiinflammatory drugs and radiologic progression of osteoarthritis? The Rotterdam Study. Arthritis Rheum. 2005;52(10):3137-42.

17. Reijman M, Hazes JM, Bierma-Zeinstra SM, Koes BW, Christgau S, Christiansen C, et al. A new marker for osteoarthritis: cross-sectional and longitudinal approach. Arthritis Rheum. 2004;50(8):2471-8.

18. Reijman M, Hazes JM, Pols HA, Bernsen RM, Koes BW, Bierma-Zeinstra SM. Role of radiography in predicting progression of osteoarthritis of the hip: prospective cohort study. BMJ. 2005;330(7501):1183.

19. Reijman M, Pols HA, Bergink AP, Hazes JM, Belo JN, Lievense AM, et al. Body mass index associated with onset and progression of osteoarthritis of the knee but not of the hip: the Rotterdam Study. Ann Rheum Dis. 2007;66(2):158-62. 
20. Kopec JA, Sayre EC, Schwartz TA, Renner JB, Helmick CG, Badley EM, et al. Occurrence of radiographic osteoarthritis of the knee and hip among african americans and whites: a population-based prospective cohort study. Arthritis Care Res (Hoboken). 2013;65(6):928-35.

21. Clockaerts S, Van Osch GJ, Bastiaansen-Jenniskens YM, Verhaar JA, Van Glabbeek F, Van Meurs JB, et al. Statin use is associated with reduced incidence and progression of knee osteoarthritis in the Rotterdam study. Ann Rheum Dis. 2012;71(5):642-7.

22. Gossec L, Tubach F, Baron G, Ravaud P, Logeart I, Dougados M. Predictive factors of total hip replacement due to primary osteoarthritis: a prospective 2 year study of 505 patients. Ann Rheum Dis. 2005;64(7):1028-32.

23. Hochberg MC. Do risk factors for incident hip osteoarthritis $(\mathrm{OA})$ differ from those for progression of hip OA? J Rheumatol Suppl. 2004;70:6-9.

24. Yusuf E, Bijsterbosch J, Slagboom PE, Kroon HM, Rosendaal FR, Huizinga TW, et al. Association between several clinical and radiological determinants with long-term clinical progression and good prognosis of lower limb osteoarthritis. PLoS One. 2011;6(10):e25426.

25. Ledingham J, Dawson S, Preston B, Milligan G, Doherty M. Radiographic progression of hospital referred osteoarthritis of the hip. Ann Rheum Dis. 1993:52(4):263-7.

26. Jordan JM, Helmick CG, Renner JB, Luta G, Dragomir AD, Woodard J, et al. Prevalence of hip symptoms and radiographic and symptomatic hip osteoarthritis in African Americans and Caucasians: the Johnston County Osteoarthritis Project. J Rheumatol. 2009;36(4):809-15.

27. Nelson AE, Braga L, Renner JB, Atashili J, Woodard J, Hochberg MC, et al. Characterization of individual radiographic features of hip osteoarthritis in African American and White women and men: the Johnston County Osteoarthritis Project. Arthritis Care Res (Hoboken). 2010;62(2):190-7.

28. Tepper S, Hochberg MC. Factors associated with hip osteoarthritis: data from the First National Health and Nutrition Examination Survey (NHANES-I). Am J Epidemiol. 1993;137(10):1081-8.

29. Baron JA, Barrett J, Katz JN, Liang MH. Total hip arthroplasty: use and select complications in the US Medicare population. Am J Public Health. 1996;86(1):70-2.

30. Dunlop DD, Song J, Manheim LM, Chang RW. Racial disparities in joint replacement use among older adults. Med Care. 2003;41(2):288-98.

31. Escarce JJ, Epstein KR, Colby DC, Schwartz JS. Racial differences in the elderly's use of medical procedures and diagnostic tests. Am J Public Health. 1993;83(7):948-54.

32. Jordan JM, Helmick CG, Renner JB, Luta G, Dragomir AD, Woodard J, et al. Prevalence of knee symptoms and radiographic and symptomatic knee osteoarthritis in African Americans and Caucasians: the Johnston County Osteoarthritis Project. J Rheumatol. 2007;34(1):172-80.

33. Radoff LS. The CES-D scale: A self-report depression scale for research in the general population. Appl Psychol Meas. 1977;1:385-401.

34. Kellgren JH, Lawrence JS. Radiological assessment of osteo-arthrosis. Ann Rheum Dis. 1957;16(4):494-502.

35. Jordan JM, Linder GF, Renner JB, Fryer JG. The impact of arthritis in rural populations. Arthritis Care Res. 1995;8(4):242-50

36. Lanyon P, Muir K, Doherty S, Doherty M. Influence of radiographic phenotype on risk of hip osteoarthritis within families. Ann Rheum Dis. 2004;63(3):259-63.

37. Burnett S, Hart DJ, Cooper C, Spector TD. A radiographic atlas of osteoarthritis. London: Springer; 1994.

38. Bruce B, Fries JF. The Stanford Health Assessment Questionnaire: dimensions and practical applications. Health Qual Life Outcomes. 2003:1:20.

39. Zhang Y, Niu J, Felson DT, Choi HK, Nevitt M, Neogi T. Methodologic challenges in studying risk factors for progression of knee osteoarthritis. Arthritis Care Res (Hoboken). 2010;62(11):1527-32.

40. Birrell F, Croft P, Cooper C, Hosie G, Macfarlane G, Silman A. Predicting radiographic hip osteoarthritis from range of movement. Rheumatology (Oxford). 2001;40(5):506-12

41. Hando BR, Gill NW, Walker MJ, Garber M. Short- and long-term clinical outcomes following a standardized protocol of orthopedic manual physical therapy and exercise in individuals with osteoarthritis of the hip: a case series. J Man Manip Ther. 2012;20(4):192-200.

42. Cibere J, Thorne A, Bellamy N, Greidanus N, Chalmers A, Mahomed N, et al. Reliability of the hip examination in osteoarthritis: effect of standardization. Arthritis Rheum. 2008:59(3):373-81.

43. Dougados M, Gueguen A, Nguyen M, Berdah L, Lequesne M, Mazieres B, et al. Requirement for total hip arthroplasty: an outcome measure of hip osteoarthritis? J Rheumatol. 1999;26(4):855-61.
44. Gosvig KK, Jacobsen S, Sonne-Holm S, Palm H, Troelsen A. Prevalence of malformations of the hip joint and their relationship to sex, groin pain, and risk of osteoarthritis: a population-based survey. J Bone Joint Surg Am. 2010:92(5):1162-9.

45. Reid GD, Reid CG, Widmer N, Munk PL. Femoroacetabular impingement syndrome: an underrecognized cause of hip pain and premature osteoarthritis? J Rheumatol. 2010;37(7):1395-404.

46. Allen KD, Golightly YM, Callahan LF, Helmick CG, Ibrahim SA, Kwoh CK, et al. Race and sex differences in willingness to undergo total joint replacement: the johnston county osteoarthritis project. Arthritis Care Res (Hoboken). 2014;66(8):1193-202.

47. Chen J, Rizzo JA, Parasuraman S, Gunnarsson C. Racial disparities in receiving total hip/knee replacement surgery: the effect of hospital admission sources. J Health Care Poor Underserved. 2013;24(1):135-51.

48. Blum MA, Ibrahim SA. Race/ethnicity and use of elective joint replacement in the management of end-stage knee/hip osteoarthritis: a review of the literature. Clin Geriatr Med. 2012;28(3):521-32.

49. Lavernia CJ, Alcerro JC, Contreras JS, Rossi MD. Ethnic and racial factors influencing well-being, perceived pain, and physical function after primary total joint arthroplasty. Clin Orthop Relat Res. 2011;469(7):1838-45.

\section{Submit your next manuscript to BioMed Central and take full advantage of:}

- Convenient online submission

- Thorough peer review

- No space constraints or color figure charges

- Immediate publication on acceptance

- Inclusion in PubMed, CAS, Scopus and Google Scholar

- Research which is freely available for redistribution

Submit your manuscript at www.biomedcentral.com/submit 